JING SHI, Ph.D. ${ }^{1}$

(Corresponding author)

E-mail: jingshi@mail.tsinghua.edu.cn

DANDAN PENG, Master ${ }^{2}$

E-mail: pengdandanedu@126.com

YAO XIAO, Ph.D. ${ }^{3}$

E-mail: xiaoyao_0307@163.com

${ }^{1}$ Department of Civil Engineering, Tsinghua University

Beijing 100084, China

2 China Center for Information Industry Development

Beijing 100048, China

${ }^{3}$ Ministry of Transport of the People's Republic of China

Beijing 100084, China
Human - Transport Interaction

Preliminary Communication

Submitted: 4 Apr. 2018

Accepted: 24 June 2019

\title{
EXPLORATION OF CONTRIBUTING FACTORS OF DIFFERENT DISTRACTED DRIVING BEHAVIOURS
}

\begin{abstract}
The motivation of this research is to explore the contributing factors of driving distraction and compare the contributing factors for three typical distracted driving behaviours: drinking water, answering a phone and using mobile phone application (APP) while driving. An online survey including a driving behaviour scale and the Theory of Planned Behaviour Questionnaire (TPB Questionnaire) was conducted to obtain data related to these driving distractions. An integral structural equation model based on the Theory of Planned Behaviour (TPB) was established to explain the factors causing three typical distracted behaviours, and the causes of differences for three typical distracted behaviours were compared. The result shows that the attitudes and perceived behaviour control are the main factors causing distracted behaviours, and the subjective norm has a significant impact on answering a phone while driving. The occurrence of a distracted driving behaviour is the consequence of behaviour intention and perceived behaviour control. These conclusions provide insights for implementing behaviour modification and traffic laws education.
\end{abstract}

\section{KEY WORDS}

driving distraction; contributing factors; structural equation model; theory of planned behaviours;

\section{INTRODUCTION}

Driving distraction has become one of the common aberrant driving behaviours, which has a big impact on the traffic safety, as well as on the efficiency of the traffic flow. Using the data of the national traffic accidents in Australia, Beanland et al. found that about 11.6\% of the severe traffic crashes resulted from distracted driving behaviours [1]. Driving distraction, which is caused by distracting objects, can be divided into internal distraction and external distraction, according to the distraction causes. It is found that the drivers are more likely to be affected by internal objects of a car compared to external objects. Internal distraction behaviours are mostly caused by secondary tasks while driving. Using mobile phones or equipment in the car, eating, drinking water, smoking, and chatting with passengers are common secondary tasks when driving [2]. Prat et al. found that nearly $20 \%$ of the drivers engaged in distracted driving behaviours related to the secondary task while driving [3]. Getting involved in the secondary task would increase the distraction occurrence and accident severity, and sufficient efforts should be made to reduce and eliminate driving distractions.

\section{LITERATURE REVIEW}

It is noteworthy that engaging in secondary tasks while driving, unavoidably causes potential safety risk. The previous studies have mainly concentrated on observing the driving stability, analysing the driver's information processing and reaction ability, and measuring the operating parameters of the car, such as speed and car-following distance. Haque et al. applied a hazard-based duration model to study the effect of distracted driving behaviours on young driver's braking behaviour, and found that distracted young drivers showed urgent and frequent braking behaviours [4]. Meanwhile, Dozza et al. found the drivers would pre-set larger transverse safety margin when using a dial phone or texting, compared to mobile phone conversation [5]. However, it is not a unique instance. Saifuzzaman et al. found out that the distracted driver would generally reduce the speed, increase headway distance and time headway in advance [6]. Distracted driving behaviours also change the decision-making ability of drivers at the intersections. Previous studies have shown that distracted drivers are less likely to stop when meeting the yellow light, which significantly increased the risk of crashes at the intersection $[7,8]$. 
Using mobile phone is a typical secondary task while driving. The distracted driving behaviour caused by mobile phone use is also common. A large number of studies have indicated that frequency of mobile phone usage (answering the phone, texting, and using mobile phone APP) while driving is significantly related to the number of traffic crashes [1-3]. A survey by Ford Motor shows that $59 \%$ of the Chinese drivers will use We Chat, a new type of social and instant messaging APP, while driving [9]. Undoubtedly, the use of We Chat and other mobile phone APPs while driving increases the frequency of distracted driving behaviours and makes driving more dangerous. However, there is hardly any literature on Chinese drivers' distracted driving behaviours related to using mobile phone APPs.

In order to reduce the driver's distracted driving behaviour, it is necessary to clarify the contributing factors for the occurrence of such aberrant driving behaviours. The TPB, which has an extensive application on exploring the motivation involved in distracted driving, was initially proposed by Ajzen [10], to explain the decision-making process of planned behaviours. According to the theory, human behaviours are conducted by behaviour intention, which is jointly influenced by three factors: attitude, subjective norm, and perceived behaviour control. In the field of transportation research, the TPB is usually used to analyse the behaviour motivation of drivers and pedestrians, which shows good applicability. Holland explored pedestrian behaviour intention of crossing the road in a dangerous situation, which indicated that attitude, subjective norm, and perceived behaviour control explained the pedestrian behaviour very well [11]. However, among the three factors, attitude played the most important role, followed by subjective norm and perceived behaviour control. Using the TPB, Walsh et al. showed that attitude and subjective norm have a decisive effect on the use of mobile phones when driving, and the influence of perceived behaviour control was quite small [12]. However, Zhou et al. found that perceived behaviour control was the most influential factor [13]; if a driver thinks they had the ability to use a mobile phone when driving, distracted behaviours caused by using mobile phones would increase considerably. To explain why people use mobile phones while driving, Zhou et al. considered compensatory decisions within the TPB, and the research discovered that the answering intention and compensatory decisions were more dependent on the way of using a mobile phone (using a mobile phone in the handheld or hands-free condition) and age rather than gender [14]. Chen et al. applied modified TPB to predict self-reported engagement behaviour in several distraction tasks, revealing that attitudes, perceived behaviour control, and descriptive norms were significant predictors of self-reported engagement [15]. It can be seen that the existing studies are focused on the analysis of one particular driving distraction; however, there is a lack of comparative study on the motivation of different driving distraction behaviours.

Based on the effectiveness of the TPB on the analysis of human behaviour decision, this study used the TPB to analyse intrinsic motivation of three typical distracted behaviours: drinking water, answering a phone, and using mobile phone APP while driving, and to compare the differences of these behaviour motivations, hoping to provide theoretical support for mitigating driving distractions.

\section{METHOD}

\subsection{Selection of typical distracted driving behaviours}

Three typical distracted driving behaviours selected in the research are: drinking water, answering a phone and using a mobile phone APP while driving. According to our pre-investigation [16], these three are common distracted driving behaviours among the Chinese drivers. It also accords with the existing literature research [3], which showed that drinking water and answering a mobile phone are very common distraction behaviours. The effects of three driving distraction behaviours on the driving performance, as well as their respective risk level, are not the same, and thus can fully reflect the driver's various distracted driving behaviours.

\subsection{Data collection for distracted driving behaviours study}

The types of data used in the studies of driving behaviours usually include: a Driver Behaviour Questionnaire (DBQ), driving simulation, and Naturalistic Driving Study (NDS) [17-19]. This paper explored the distracted driving behaviours using DBQ data obtained from an online survey. Shi et al. surveyed the Chinese drivers' driving behaviour through a paper questionnaire and an online questionnaire, respectively, and illustrated that the data obtained by two methods were highly consistent [17], which showed that using an online survey is a feasible and effective way for aberrant driving behaviours study in China. Accordingly, in this study, the method of online questionnaire survey was used to obtain data related to the driver's distracted behaviours. The questionnaire consists of two sections. In the first section, the basic information about the drivers was collected, including gender, age, education level, driving age, driving frequency, family income, family size, and occupation related to the driving behaviours [21-24]. In addition, this section also included questions about the frequency of different distracted behaviours and the driver's assessment of 
the risk of these distracted behaviours, and the method of the driver's risk assessment for distracted behaviour referred from the Likert scale.

The second section was designed with the TPB as the framework. Four dimensions were investigated, namely, the driver's attitude, subjective norm, perceived behaviour control and behaviour intention on the basis of the three secondary tasks while driving, i.e., drinking water, answering a phone and using a mobile phone APP, respectively. A seven-degree Likert scale of 12 questions with each dimension evaluated on three questions in order to reduce the random errors, is shown in Table 1 (taking "answering a phone" for example). Based on the scales, the participants would answer the questions by selecting an option ranged from 1 to 7 to represent different levels. The second section of the questionnaire was designed based on the Theory of Planned Behaviour questionnaire (TPB Questionnaire) [11, 12, 14], and certain adjustments were made according to the content of the study.

The questionnaire surveys were conducted via the "SOJUMP" website to obtain the data for this research. A link of the survey entitled "An Investigation of Driving Distraction for Car Drivers in Beijing" was released on the website http://www.sojump.com/jq/5781592. aspx. The survey was conducted from September 10 to 24,2015 . A total of 469 questionnaires were received. Among them, 45 invalid questionnaires were removed because of incomplete content and abnormal fill-out time, and finally 424 effective questionnaires were obtained.

\subsection{Structural equation modelling}

The Structural Equation Model (SEM) is a method for multivariate data analysis, which is characterised by the ability to estimate and identify abstract concepts and is generally used for verifiable factor analysis. Variables in structural equation models can be divided into two categories: observed variables (OV) and latent variables. Latent variables, namely abstract concepts, are the object of the study, while observational variables are the means of measurement and the quantitative indicators of the latent variables. The advantage of the structural equation model is that it estimates the measurement error of the variable, and the model can be evaluated as a whole.

\section{RESULTS}

\subsection{Descriptive statistics and analysis of variance}

Among 424 valid questionnaire respondents, the proportion of men and women is similar, accounting for $54.7 \%$ and $45.3 \%$, respectively. The age ranged from 18 to 65 years, and $52 \%$ of participants were between 26 to 35 years old. The reported occupations were mostly (60.6\%) company staff, and monthly family income concentrated on RMB10,000-30,000 Yuan (59.7\%). In the current sample, $71.4 \%$ of the respondents are married, and $58 \%$ of them have children, and more than $50 \%$ of the driver's driving years are distributed between 1 and 6 years. Most (91.5\%) of the drivers reported fewer than three accidents in the past three years.

The analysis of variance (ANOVA) was used to identify how different personal attributes are related to the frequency of distracted driving behaviours. The ratings of frequency ranged from 1 to 7: 1 - never, 2 - hardly ever, 3 - occasionally, 4 - sometimes, 5 - often, 6 frequently, 7 - nearly all the time. The result shows that age, marital status, education level, vehicle ownership, and the number of family members had no significant effect on the frequency of distraction. Gender, driving experience, driving frequency, family monthly income and the number of traffic crashes in the past three years have significant effects on the frequency of distracted driving behaviours, as shown in Table 2.

Table 1 - Questions of each dimension (answering a phone)

\begin{tabular}{||l|l||}
\hline \multicolumn{1}{|c|}{ Dimension } & $\begin{array}{c}\text { Question (please select a number from "1" to "7" where "1" means "I strongly disagree" and "7" } \\
\text { means “I strongly agree") }\end{array}$ \\
\hline \hline \multirow{3}{*}{ Attitude } & $\begin{array}{l}\text { 1. Do you agree that answering a phone should be allowed during driving? } \\
\text { 2. Do you agree that answering a phone would affect normal driving? } \\
\text { 3. Do you agree that answering a phone should be avoided during driving? }\end{array}$ \\
\hline Subjective norm & $\begin{array}{l}\text { 1. Do you agree that your friends would like you to answer their phone call during driving? } \\
\text { 2. Do you agree that your family would like you to answer their phone call during driving? } \\
\text { 3. Do you agree that your upper division would like you to answer their phone call during driving? }\end{array}$ \\
\hline Perceived behaviour \\
control & $\begin{array}{l}\text { 1. Do you agree that answering the phone during driving is difficult for you? } \\
\text { 2. Do you agree that answering the phone during driving is dangerous for you? } \\
\text { 3. Do you agree that you are capable of answering the phone and driving at the same time? }\end{array}$ \\
\hline Behaviour intention & $\begin{array}{l}\text { 1. Do you agree that it is possible for you to answer the phone during driving? } \\
\text { 2. Do you agree that you would want to answer the phone during driving? } \\
\text { 3. Do you agree that you will answer the call during driving in the future? }\end{array}$ \\
\hline
\end{tabular}


Table 2 - ANOVA results for the frequency of distracted driving behaviour

\begin{tabular}{|c|c|c|c|c|}
\hline \multirow{2}{*}{\multicolumn{2}{|c|}{ Model }} & \multicolumn{3}{|c|}{ Frequency of distracted driving behaviour } \\
\hline & & Mean & $F$ & $p$ \\
\hline \multirow{2}{*}{ Gender } & Male & 3.05 & \multirow{2}{*}{15.502} & \multirow{2}{*}{$0.000^{*}$} \\
\hline & Female & 2.67 & & \\
\hline \multirow{4}{*}{ Driving experience } & within 1 year & 2.55 & \multirow{4}{*}{4.153} & \multirow{4}{*}{$0.006^{*}$} \\
\hline & $1-3$ years & 2.95 & & \\
\hline & $4-6$ years & 2.96 & & \\
\hline & more than 6 years & 2.98 & & \\
\hline \multirow{4}{*}{$\begin{array}{l}\text { Driving frequency } \\
\text { (days per week) }\end{array}$} & $\leq 1$ day & 2.56 & \multirow{4}{*}{8.228} & \multirow{4}{*}{$0.000^{*}$} \\
\hline & 2-3 days & 2.95 & & \\
\hline & 4-5 days & 2.93 & & \\
\hline & 6-7 days & 3.25 & & \\
\hline \multirow{3}{*}{$\begin{array}{l}\text { Family monthly income (RMB } \\
\text { yuan) }\end{array}$} & $\leq 10,000$ & 2.54 & \multirow{3}{*}{11.369} & \multirow{3}{*}{$0.000^{*}$} \\
\hline & $10,000-20,000$ & 3.04 & & \\
\hline & $>20,000$ & 3.02 & & \\
\hline \multirow{3}{*}{$\begin{array}{l}\text { Number of traffic crashes in the } \\
\text { past three years }\end{array}$} & 0 & 2.56 & \multirow{3}{*}{24.890} & \multirow{3}{*}{$0.000^{*}$} \\
\hline & $1-2$ & 3.13 & & \\
\hline & $\geq 3$ & 3.47 & & \\
\hline
\end{tabular}

* significant at 0.05 level

The above results are calculated based on the data collected from the questionnaire survey. Overall, males engage in more distracted driving behaviours than females while driving. Drivers who have driving experience of more than one year have more distracted driving behaviours than novice drivers. Drivers with higher driving frequency are more frequently distracted while driving. Drivers with high family income reported more distracted driving behaviours, which may be related to their high driving frequency. The reported number of traffic crashes in the past three years is also significantly related to the frequency of distracted driving behaviours. Drivers who have more traffic crashes are more frequently engaged in driving distraction.

\subsection{Comparison of factors for three distracted driving behaviours}

The structural equation model in this study included five latent variables: attitude, subjective norm, perceived behaviour control, behaviour intention and behaviour. The model was measured by 14 observed variables, all obtained through questionnaires.

For each distracted behaviour, based on the TPB, a single structural equation model is used to analyse the influence of attitudes, subjective norms, and perceived behaviour controls on their behaviour intentions, as shown in Table 3.

Table 3 - Fit degrees and $\beta$ values for Three models

\begin{tabular}{||l|c|c|c||}
\hline & $\begin{array}{c}\text { SEM 1: } \\
\text { Answering a phone }\end{array}$ & $\begin{array}{c}\text { SEM 2: } \\
\text { Using mobile phone APP }\end{array}$ & $\begin{array}{c}\text { SEM 3: } \\
\text { Drinking water }\end{array}$ \\
\hline \hline Chi square value & 155.4 & 126.9 & 125.5 \\
\hline Degrees of freedom & 46 & 46 & 46 \\
\hline Root-mean-square error of approximation & 0.075 & 0.064 & 0.064 \\
\hline Goodness-of-fit & 0.941 & 0.954 & 0.954 \\
\hline Attitudes--> behaviour intention & $0.651^{*}$ & $1.063^{*}$ & $1.240^{*}$ \\
\hline Subjective norms --> behaviour intention & 0.115 & -0.257 & -0.462 \\
\hline $\begin{array}{l}\text { Perceived behaviour control --> behaviour } \\
\text { intentions }\end{array}$ & $-0.173^{*}$ & -0.116 & -0.142 \\
\hline Perceived behaviour control --> behaviour & $-0.219^{*}$ & $-0.219^{*}$ & $-0.262^{*}$ \\
\hline Behaviour intentions --> behaviour & $0.540^{*}$ & $0.435^{*}$ & $0.420^{*}$ \\
\hline
\end{tabular}

* significant at 0.01 level 
Comparing the data of three models, it can be found that the main influencing factors of the three driving distractions are different. The three driving distractions are positively influenced by attitudes, meaning that the driver has a positive attitude towards distraction. If the driver realizes that a driving distraction is a wrong act, the intention of the act will be significantly reduced. Drinking water and using mobile phone APP, these two acts are particularly affected by the attitude (corresponding $\beta$ values are 1.063 and 1.240, respectively). The pattern of significant and non-significant predictors for using mobile phone APP and drinking water is identical. But answering a phone differs only in the addition of perceived behaviour control as a predictor of intention.

If a driver is aware of the risk, the distracted driving behaviour will be significantly reduced. As it can be seen from the results of the structural equation model, attitude and perceived behaviour control are two main factors that affect the driver's distraction behaviour. The impact of subjective norm is relatively small, not significant.

\subsection{Results of integral structural equation model}

In order to eliminate the correlation of the observed variables within a single structural equation model and to improve the stability and reliability of the structural equation model, an integral structural equation model for distracted behaviour was established. Table 4 shows the corresponding relations between the observed variables and the latent variables.

Behaviour latent variables were measured by two observed variables: occurrence frequency (OF) and number of occurrence (NO), obtained in the first section of the questionnaire, and the other four latent variables are measured by 12 observed variables from the second section of the questionnaire. The corresponding 14 observed variables of three distracted driving behaviours are shown in Table 4.

The combinations of the observed variables for three distracted driving behaviours were taken as observed variables of the entire structural equation model, and the specific process was also shown in Table 4. Take the attitude variable for example, the average value of the two observed variables was calculated with regard to the attitude towards answering the call behaviour (corresponding to OV 1 and OV 3, OV 2 was deleted because of its low validity), as a latent variable "attitude 1" (A 1). The average value of the two variables was calculated with regard to the attitude towards using mobile phone APP behaviour (corresponding to OV 1 and OV 3), as a latent variable "attitude 2" (A 2). In exactly the same way, the latent variable "attitude 3" (A 3) towards the drinking water behaviour was calculated, and then the three variables were taken to measure the attitude of the driver's distracted driving behaviours. Similarly, the subjective norm, perceived

Table 4 - Latent variable, observed variable and combined variable of three distracted driving behaviours

\begin{tabular}{|c|c|c|}
\hline Latent variable & Observed variable & Combined observed variable \\
\hline A & $\begin{array}{l}\text { OV 1: Whether it is allowed while driving } \\
\text { OV 2: Whether it affects the normal driving } \\
\text { OV 3: Whether it is to be avoided }\end{array}$ & $\begin{array}{l}\text { A1 (answering the phone) } \\
\text { A2 (using phone APP) } \\
\text { A3 (drinking water) }\end{array}$ \\
\hline S & $\begin{array}{l}\text { OV 4: Whether you agree to the topic that friends hope you answer } \\
\text { the call / use mobile phone APP/drink water when driving } \\
\text { OV 5: Whether the driver agrees to the topic that family hopes you } \\
\text { answer the call / use mobile phone APP/drink water when driving } \\
\text { OV 6: Whether the driver agrees to the topic that the upper division } \\
\text { hopes you answer the call /use mobile phone APP/drink water } \\
\text { when they call you on the phone. }\end{array}$ & $\begin{array}{l}\text { S1 (answering the phone) } \\
\text { S2 (using phone APP) } \\
\text { S3 (drinking water) }\end{array}$ \\
\hline $\mathrm{P}$ & $\begin{array}{l}\text { OV 7: The difficulty when answering the phone/using mobile phone } \\
\text { APP/drinking water during driving. } \\
\text { OV 8: The danger when answering the phone/using mobile phone } \\
\text { APP/drinking water during driving. } \\
\text { OV 9: Whether the two things can be done at the same time. }\end{array}$ & $\begin{array}{l}\text { P1 (answering the phone) } \\
\text { P2 (using phone APP) } \\
\text { P3 (drinking water) }\end{array}$ \\
\hline $\mathrm{BI}$ & $\begin{array}{l}\text { OV 10: The possibility of answering the call/using mobile phone } \\
\text { APP/drinking water } \\
\text { OV 11: Whether one wants to receive calls/use mobile phone APP/ } \\
\text { drink water or not } \\
\text { OV 12: Willingness to answer the call /use mobile phone APP/ } \\
\text { drink water in the future }\end{array}$ & $\begin{array}{l}\text { BI } 1 \text { (answering the phone) } \\
\text { BI } 2 \text { (using phone APP) } \\
\text { BI } 3 \text { (drinking water) }\end{array}$ \\
\hline$B$ & $\begin{array}{l}\text { OV 13: The occurrence of driving distraction } \\
\text { OV 14: How often do drivers experience driving distraction }\end{array}$ & $\begin{array}{l}\text { B1 (answering a phone) } \\
\text { B2 (using phone APP) } \\
\text { B3 (drinking water) }\end{array}$ \\
\hline
\end{tabular}

Note: $A$ - attitude, $S$ - subjective norm, $P$ - perceived behaviour control, BI - behaviour intention, $B$ - behaviour 
behaviour control, behaviour intention and behaviour were calculated with the same method, and finally 15 observed variables were shown in the right side of Table 4. Before establishing the integral structural equation model, the reliability of the data was tested with the aid of the statistical software AMOS 17.0.

Based on the combined variables in Table 4, the structural equation model of the distracted behaviour was established. It is important to note that $A 1, S 1$, P1, BI1 and B1 correspond to the same distracted behaviour, answering a phone. Factor loadings and the combined reliability were calculated respectively, as shown in Table 5. The higher the factor loading, the better it can explain the observed variable, reflecting the validity of questions surveyed to a certain extent.

The results show that a vast majority of factor loadings are greater than 0.6 , and the combined reliability is greater than 0.5 , which indicates that the data have good reliability and validity. The final fitted structural equation model is shown in Figure 1, Chi-square value $=79.0$, degrees of freedom $=52$, RMSEA $=0.035<$ $0.06, \mathrm{GFI}=0.976>0.9, \mathrm{AGFI}=0.945>0.9, \mathrm{NFI}=$ $0.981>0.9$. High fitting degree shows that the TPB can explain the driver's distracted behaviours well.

The behaviour intention is influenced by attitude, subjective norm and perceived behaviour control, and the direct effect of attitude on intention is 0.678 (standard error $\mathrm{SE}=0.226$ ), with the greatest degree of influence. Additionally, the direct effect of perceived behaviour control on the behaviour intention is -0.100 $(\mathrm{SE}=0.063)$, which shows that the driver's perception of risk will significantly reduce their behaviour intentions. The direct effect of subjective norm on the behaviour intention is 0.198 ( $\mathrm{SE}=0.195)$, indicating that the social pressure from the family and office leaders
Table 5 - Factor loading and combined reliability coefficient of three distracted driving behaviours

\begin{tabular}{||c|c|c||}
\hline \hline Factor & Factor loading & Combined reliability \\
\hline \hline A1 & 0.705 & \multirow{2}{*}{0.580} \\
\hline A2 & 0.602 & \\
\hline A3 & 0.676 & \multirow{2}{*}{0.569} \\
\hline S1 & 0.602 & \\
\hline S2 & 0.600 & \multirow{2}{*}{0.518} \\
\hline S3 & 0.660 & \\
\hline P1 & 0.714 & \multirow{2}{*}{0.548} \\
\hline P2 & 0.595 & \\
\hline P3 & 0.587 & \\
\hline BI1 & 0.842 & \\
\hline BI2 & 0.604 & \multirow{2}{*}{0.699} \\
\hline BI3 & 0.625 & \\
\hline B1 & 0.840 & \\
\hline B2 & 0.689 & \\
\hline B3 & 0.775 & \\
\hline
\end{tabular}

will cause the driver to produce distraction, but the effect is not significant. The direct effect of the behaviour intention to behaviour is 0.415 ( $\mathrm{SE}=0.057$ ), which is less than 0.5 , so the fitting result indicates a significant relationship between the behaviour intention and behaviour. The direct effect of the perceived behaviour control on the behaviour is -0.292 ( $\mathrm{SE}=0.088$ ), which is also significant.

\section{DISCUSSION}

The differences of distracted driving behaviours are related to a variety of demographic data. One demographic result indicates that males have more

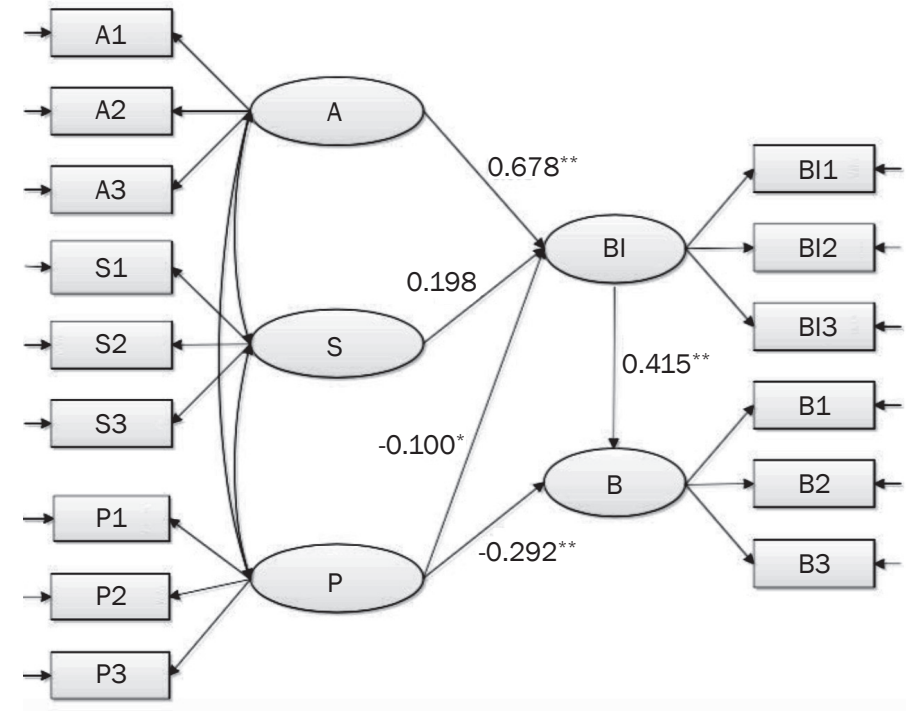

Figure 1 - Integral structural equation model ( ${ }^{*}$ significant at 0.05 level, ${ }^{* *}$ significant at 0.01 level) 
distracted driving behaviours than females while driving. A possible explanation for this is that men are involved in more business calls. This conclusion is consistent with the research conducted by Walsh et al., who found that male drivers and business drivers were more likely to be engaged with a phone while driving [12]. Another demographic result shows that drivers who experience driving more than one year are more distracted than novice drivers, and the driving frequency and frequency of distraction are positively correlated. It may be that the new drivers are more cautious, since they had just passed the most stringent safety driving training. The income levels also have a relation to distracted driving behaviour; the drivers with high income were observed to be more distracted. The number of traffic crashes of the past three years also has obvious relevance to the occurrence frequency of the distracted driving behaviour. The drivers who suffered more traffic crashes had higher frequency of distracted driving behaviours, and gave higher scores to subjective risk assessment of distracted driving behaviours [16], indicating that the driver ignored the effect of distracted driving behaviours on traffic safety.

According to the comparison of three typical distracted driving behaviours, using mobile phone APPs is particularly affected by the attitude (corresponding value in Table 3 is 1.063). However, according to the pre-investigation [16], following chatting with passengers, adjusting in-vehicle equipment and drinking water, using mobile phone APPs has been a common distracted driving behaviour. Despite convenience of mobile phone APPs, it is worth noting that one should realize the safety risks that using of mobile phone APPs brings while driving.

The integral structural equation model shows that the attitude and perceived behaviour control have significant influence on the intention of distraction. This finding is consistent with the research by Walsh [12], indicating that the attitude is the most consistent prediction of intention to answer a mobile phone while driving. It is found that the behaviour intention and the perceived behaviour control jointly determine the occurrence of behaviour, and the subjective norm has a significant impact on answering the mobile phone.

Our findings could give some suggestions to implement the behaviour modification and interventions, as well as traffic laws education. Firstly, traffic police could focus on a specific group according to different demographic statistics. For example, a corresponding driving training and education could be carried out for male drivers, who have more than one year of driving experience, higher income and higher driving frequency. Secondly, considering the fact that the attitude and perceived behaviour control are shown to have significant influence on the intention of distraction, the models of attitude change could be designed to test if it could bring improvement in modifying the driving distraction.

However, the findings of this study should be interpreted in the light of its limitations. The first limitation is the coverage of the sample. An online questionnaire survey was used, which could lead to missing out of some drivers who do not often go online. Although the sample has been randomly selected, the number of samples is still relatively small. In the future, it would be beneficial to take more reasonable sampling methods, in order to get improved results. Second, in this study three typical distracted driving behaviours were selected: drinking water, answering a phone and using mobile phone APP while driving. Some other distracted driving behaviours, like talking with passengers, are excluded due to the consideration of the feasibility of the investigation and the representativeness of the behaviours. Third, it has been found that people overor underestimate their frequencies of mobile phone use when compared to their actual distraction records [25], although self-reported measures provide a reasonable indication of people behaviour [26]. Additionally, no legitimacy of hand-held mobile phone use in China may have affected the accuracy of self-reported frequencies for people who engaged in driving distraction.

\section{CONCLUSION}

This research provides two important contributions to the literature. Firstly, the intrinsic motivation of three typical distracted driving behaviours and factors causing these distracted driving behaviours were analysed in this study. The differences among the three typical distracted driving behaviours are found in attitude, perceived behaviour control, subjective norm, behaviour intention, and behaviour. Secondly, the integral structural equation model shows that the attitudes and perceived behaviour control for distracted driving behaviour have a significant impact on the intention of distracted driving behaviour, suggesting that the awareness of the risk of driving distractions could reduce the occurrence of such aberrant driving behaviour. Hence, we can strengthen the driver's awareness of the dangers of distracted driving behaviour, and further modify the aberrant driving behaviour. Our findings could also give some suggestions to implement behaviour modification and interventions as well as traffic laws education.

For the future work, we could find more contents to this study; for instance, further exploration could focus on testing the integral structural equation model in different driver groups. Besides, the specific measures taken to reduce the driving distractions occurrence are the next important issue to be investigated based on the results of this study. 


\section{ACKNOWLEDGEMENT}

We acknowledge the financial support from the National Natural Science Foundation of China (No. 51578319).

石京，教授，博士 ${ }^{1}$

(通讯作者)

邮箱: jingshi@mail.tsinghua.edu.cn

彭丹丹, 硕士 ${ }^{2}$

邮箱: pengdandanedu@126.com

肖遥, 博士 ${ }^{3}$

邮箱: xiaoyao_0307@163.com

1 清华大学 土木工程系

北京，中国100084

2 中国电子信息产业发展研究院

北京，中国100048

3 中华人民共和国交通运输部

北京，中国100084

不同分心驾驶行为的成因探究

\section{摘要}

本研究的目的在于探究驾驶分心的成因, 并比较三种 典型的分心驾驶行为的成因: 喝水、接听电话和驾驶时使 用手机应用 ( APP) 。研究采用包括驾驶行为量表和计划 行为问卷 ( $T P B$ 问卷) 理论的在线调查方法, 获取了与驾 驶分心相关的数据。基于计划行为理论（TPB）建立了结 构方程模型, 解释了导致三种典型驾驶分心行为的成因, 并比较了三种典型驾驶分心行为的差异和原因。结果表 明, 态度和感知行为控制是导致分心行为的主要因素, 主 观规范对驾驶时接听电话有显著影响。分心驾驶行为的发 生是行为意图和感知行为控制的结果。这些结论为实施行 为矫正和交通法规教育提供了依据。

\section{关键词}

分心驾驶; 影响因素; 结构方程模型; 计划行为理论

\section{REFERENCES}

[1] Beanland V, Fitzharris M, Young KL. Driver inattention and driver distraction in serious casualty crashes: Data from the Australian National Crash In-depth Study. Accident Analysis \& Prevention. 2013;54: 99-107.

[2] Carney C, Harland, KK, McGehee DV. Using event-triggered naturalistic data to examine the prevalence of teen driver distractions in rear-end crashes. Journal of Safety Research. 2016;57: 47-52.

[3] Prat F, Planes M, Gras ME. An observational study of driving distractions on urban roads in Spain. Accident Analysis \& Prevention. 2015;74: 8-16.

[4] Haque MM, Washington S. The impact of mobile phone distraction on the braking behaviour of young drivers: a hazard-based duration model. Transportation Research Part C: Emerging Technologies. 2015;50: 13-27.

[5] Dozza M, Flannagan CA, Sayer JR. Real-world effects of using a phone while driving on lateral and longitudinal control of vehicles. Journal of Safety Research. 2015;55: 81-87.

[6] Saifuzzaman M, Haque MM, Zheng Z, Washington S.
Impact of mobile phone use on car-following behaviour of young drivers. Accident Analysis \& Prevention. 2015;82:10-19.

[7] Huth V, Sanchez Y, Brusque C. Driver's phone use at red traffic lights: A roadside observation study comparing calls and visual-manual interactions. Accident Analysis \& Prevention. 2015;74: 42-48.

[8] Xiong $\mathrm{H}$, Narayanaswamy $\mathrm{P}$, Bao S. How do drivers behave during indecision zone maneuvers?. Accident Analysis \& Prevention. 2015;96: 274-279.

[9] Severely Punished Heavy Penalties "bow driver". [homepage on the Internet]. c2017 [updated 2017 May 5; cited 2017 May 9]. Available from: http://mini. eastday.com/a/170502090747672.html

[10] Ajzen I. The theory of planned behaviour. Organizational Behaviour and Human Decision Processes. 1991;50(2): 179-211.

[11] Holland C, Hill R. The effect of age, gender and driver status on pedestrians' intentions to cross the road in risky situations. Accident Analysis \& Prevention. 2007;39(2): 224-237.

[12] Walsh SP, White KM, Hyde MK. Dialing and driving: Factors influencing intentions to use a mobile phone while driving. Accident Analysis \& Prevention. 2008;40(6): 1893-1900.

[13] Zhou R, Wu C, Rau PP. Young driving learners' intention to use a handheld or hands-free mobile phone when driving. Transportation Research Part F: Traffic Psychology and Behaviour. 2006;12(3): 208-217.

[14] Zhou R, Rau PP, Zhang W. Mobile phone use while driving: Predicting driver's answering intentions and compensatory decisions. Safety Science. 2012;50(1): 138-149.

[15] Chen HYW, Donmez B, Hoekstra-Atwood L, Marulanda S. Self-reported engagement in driver distraction: An application of the Theory of Planned Behaviour. Transportation Research Part F: Traffic Psychology and Behaviour. 2016;38: 151-163.

[16] Xiao Y. Analyzing and modeling of the influence of driving distraction on traffic safety and traffic efficiency. Tsinghua University; 2016.

[17] Shi J, Bai Y, Ying X. Aberrant driving behaviours: A study of drivers in Beijing. Accident Analysis \& Prevention. 2010;42(4): 1031-1040.

[18] $\mathrm{Wu} \mathrm{J,} \mathrm{Xu} \mathrm{H.} \mathrm{The} \mathrm{influence} \mathrm{of} \mathrm{road} \mathrm{familiarity} \mathrm{on} \mathrm{distract-}$ ed driving activities and driving operation using naturalistic driving study data. Transportation Research Part F: Traffic Psychology and Behaviour. 2018;52: 75-85.

[19] Shi J, Liu M. Impacts of differentiated per-lane speed limit on lane changing behaviour: A driving simulator-based study. Transportation Research Part F: Traffic Psychology and Behaviour. 2019;60: 93-104.

[20] Charlton JL, Catchlove M, Scully M, Koppel S, Newstead S. Older driver distraction: a naturalistic study of behaviour at intersections. Accident Analysis \& Prevention. 2013;58: 271-278.

[21] Trisko J, Ferraro FR. Younger and Older adults' opinions on driver distractions and potential cellular phone Laws. Psychological Record. 2014;64(3): 503-507.

[22] Wu J, Yan X, Radwan E. Discrepancy analysis of driving performance of taxi drivers and non-professional 
drivers for red-light running violation and crash avoidance at intersections. Accident Analysis \& Prevention. 2016;91: 1-9.

[23] Lin PC, Chen SI. The effects of gender differences on the usability of automotive on-board navigation systems - A comparison of 2D and 3D display. Transportation Research Part F: Traffic Psychology and Behaviour. 2013;19: 40-51.

[24] Papadakaki M, Tzamalouka G, Gnardellis C, Lajunen TJ, Chliaoutakis J. Driving performance while using a mobile phone: a simulation study of Greek professional drivers. Transportation Research Part F: Traffic Psychology and Behaviour. 2016;38: 164-170.

[25] Cohen AA, Lemish D. Real time and recall measures of mobile phone use: Some methodological concerns and empirical applications. New Media \& Society. 2003;5: 167-183.

[26] Podsakoff PM, Organ DW. Self-report in organizational research: problems and prospects. Journal of Management. 1986;12: 531-544. 